\section{Endoscope-assisted superior septal approach for resection of left atrial myxoma}

Yoshio Misawa, MD, Tsutomu Saito, MD, Katsuo Fuse, MD, and Yasunori Sohara, MD, Tochigi, Japan

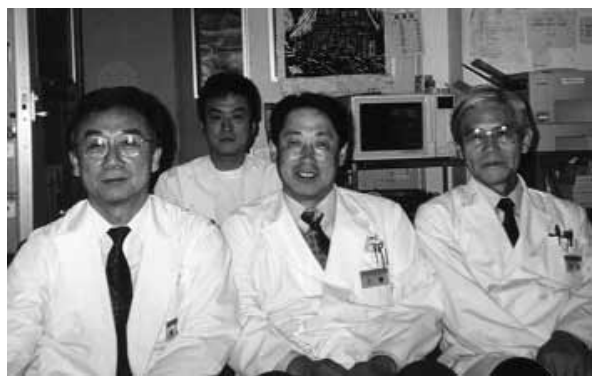

Drs Sohara, Saito, Misawa, and Fuse (left to right)

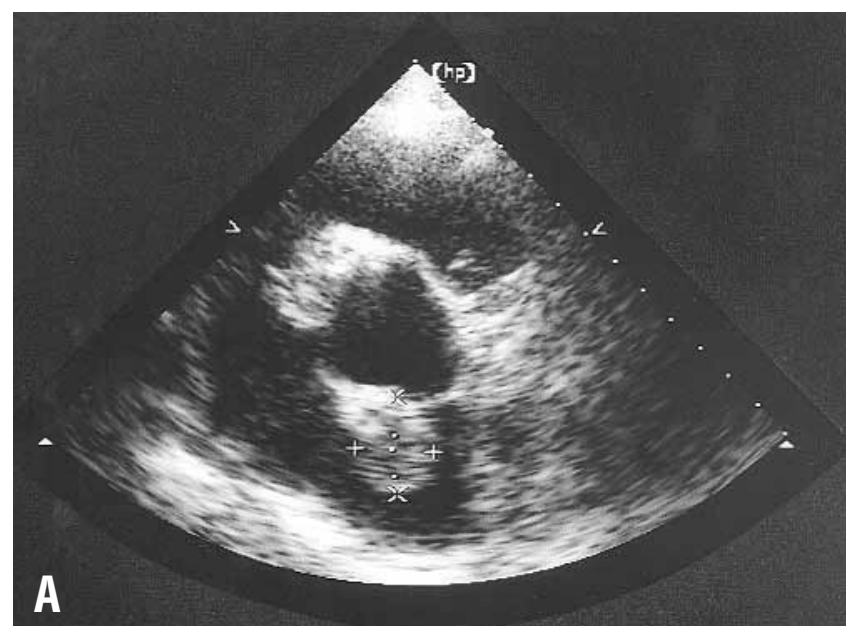
through a conventional median sternotomy, and moderate hypothermia and blood cardioplegic solution were used for myocardial protection.

The right atrium and atrial septum were incised. A thoracoscope, which is used for routine endoscopic thoracic surgery in our institute, was inserted through the atrial septotomy and revealed that the stalk of the tumor was located on the superior wall of the left atrium (Figure 2). The incision was extended from the atrial septum to the superior aspect of the left atrium, without incising the stalk. During thoracoscopic observation, the incision was completed along the superior wall of the left atrium. The stalk was excised together with an adjacent $5 \mathrm{~mm}$ of left atrial intima. The intimal defect was closed by means of direct suture without a patch. Myocardial ischemic time was 55 minutes. Pathologic

From the Department of Thoracic and Cardiovascular Surgery, Jichi Medical School, Tochigi, Japan.

Received for publication May 5, 2001; accepted for publication June 5, 2001.

Address for reprints: Yoshio Misawa, MD, Department of Thoracic and Cardiovascular Surgery, Jichi Medical School, 3311-1 Yakushiji, MinamiKawachi, Tochigi, 329-0498, Japan (E-mail: tcvmisa@jichi.ac.jp).

J Thorac Cardiovasc Surg 2002; 123:357-8

Copyright (C 2002 by The American Association for Thoracic Surgery $0022-5223 / 2002 \$ 35.00+0 \quad \mathbf{1 2 / 5 4 / 1 1 7 8 3 0}$

doi: $10.1067 / \mathrm{mtc} .2002 .117830$

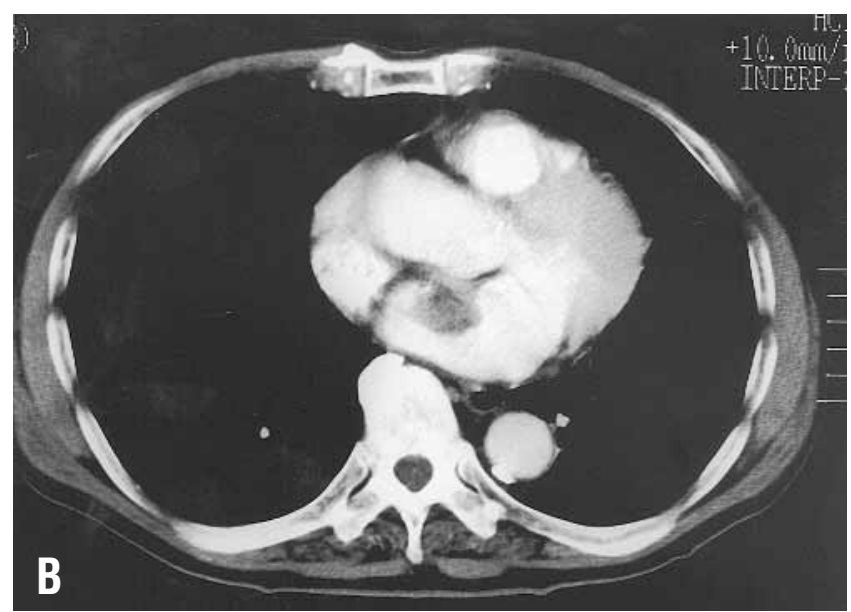

Figure 1. Preoperative echocardiographic (A) and computed tomographic (B) findings. An echocardiogram shows a $2.4 \times$ 2.3-mm mass in the left atrium beneath the ascending aorta. $A$ round mass was located on the superior wall of the left atrium, and the left atrium was not enlarged.

examination showed a completely resected $28 \times 25 \times 17-\mathrm{mm}$ mass compatible with cardiac myxoma. The patient was given pilsicainide hydrochloride (Sunrythm) to control paroxysmal atrial fibrillation. He was discharged with no complications. 


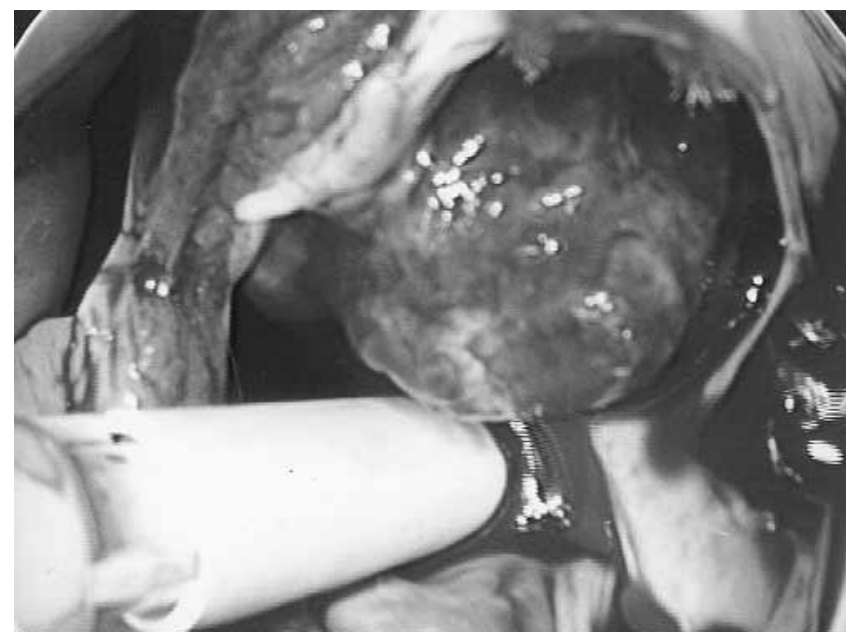

Figure 2. An intraoperative endoscopic view. The mass with a smooth surface was recognized (in the right upper quadrant) through thoracoscopic views, and the stalk originated from the superior wall of the left atrium.

\section{Discussion}

Recent sophisticated endoscopic techniques have provided surgeons with new surgical options. In cardiac surgery, procedures such as atrial septal defect repair and mitral valve surgery have been successfully performed endoscopically. ${ }^{1,2}$ The endoscope can provide an excellent operative view, especially in a small operative field. The superior septal approach for mitral valve surgery can also provide a wide operative field, contributing to safety and surgeon confidence. In our use of the superior approach for mitral valve surgery, we have encountered no intractable arrhythmias. ${ }^{3}$

Our patient's small atrium and tumor site prevented us from observing the tumor stalk by means of the conventional transseptal view. With endoscopic examination, the anatomy of the tumor was clarified, and subsequent operative procedures were easily performed. Our thoracoscope was not flexible because it was designed for use in thoracic surgery. Use of a flexible endoscope in intracardiac procedures would be even more desirable in cases such as ours. With further innovation in endoscopic instruments, complex surgical procedures requiring subtle maneuvers will be possible with endoscopic assistance. Our case exemplifies the increasing usefulness of endoscopeassisted cardiac surgery.

\section{References}

1. Chang CH, Lin PJ, Chu JJ, Liu HP, Tsai FC, Lin FC, et al. Videoassisted cardiac surgery in closure of atrial septal defect. Ann Thorac Surg. 1996;62:697-701.

2. Lin PJ, Chang CH, Chu JJ, Liu HP, Tsai FC, Chu PH, et al. Videoassisted mitral valve operations. Ann Thorac Surg. 1996;61:1781-6.

3. Misawa Y, Fuse K, Kawahito K, Saito T, Konishi H. Conduction disturbances after superior septal approach for mitral valve repair. Ann Thorac Surg. 1999;68:1262-5. 